\title{
THE ANTECEDENT FACTOR OF TOURISTS' INTENTION TO CONSUME TRADITIONAL FOOD
}

\author{
Kokom KOMARIAH* \\ Yogyakarta State University, Department of Culinary Art Vocational Education, Indonesia, e-mail: kokom@uny.ac.id
}

Abdul Rasid Bin Abdul RAZZAQ

Universiti Tun Hussein Onn Malaysia, Faculty of Technical Education, Malaysia, e-mail: rasid@uthm.edu.my

\author{
Mutiara NUGRAHENI
}

Yogyakarta State University, Department of Culinary Art Vocational Education, Indonesia, e-mail: mutiara_nugraheni@uny.ac.id

\author{
Badraningsih LASTARIWATI
}

Yogyakarta State University, Department of Culinary Art Vocational Education, Indonesia, e-mail: badra@uny.ac.id

Tuatul MAHFUD

Hospitality Department, Balikpapan State Polytechnic, Indonesia, e-mail: tuatul.mahfud@poltekba.ac.id

\begin{abstract}
Citation: Komariah, K., Razzaq, A.R.B.A., Nugraheni, M., Lastariwati, B., \& Mahfud, F. (2020). THE ANTECEDENT FACTOR OF TOURISTS' INTENTION TO CONSUME TRADITIONAL FOOD. GeoJournal of Tourism and Geosites, 32(4), 1209-1215. https://doi.org/10.30892/gtg.32403-559
\end{abstract}

\begin{abstract}
Traditional food has become one of the essential aspects of developing culinary tourism. However, there are still limited stu dies that discuss the tourists' intention to consume traditional food when they tour. This study aims to reveal the antecedent factors of the intention to consume the traditional food of tourists when traveling. Data were randomly collected through an online questionnaire from local Malaysian and Indonesian tourists. Structural equation modelling (SEM) analysis is used to analyze the path between the antecedent factors forming the intention of tourists to consume traditional food. The results of the study show that attitude, subjective norms, and behavioural control factors are essential antecedents to form the intention of tourists to consume traditional food. Also, behavioural control is proven to be a primary mediator to strengthen the influence of attitude and subjective norms on the intention of tourists to consume traditional food during their trips. The results of this study have implications for tourism practitioners in developing new culinary tourism based on economic potential (traditional food).
\end{abstract}

Key words: traditional food, ethnic food, food tourism, consumption intention, cross-cultural

\section{INTRODUCTION}

Culinary tourism has a significant role in the development of sustainable tourism and has a role in improving the country's economy (Ian, 2016; Sims, 2009). This condition makes sense because the potential for culinary tourism can increase the tourists' interest to visit a country as a tourist destination, and ultimately simultaneously also affect the country's economic improvement. Traditional food (TF) is always closely related to tourism because when visiting new tourist destinations, tourists also pay attention to the culinary habits and traditions of the local population. Now, studies of culinary tourism have been widely discussed in various countries (Ahlawat et al., 2019; Ellis et al., 2018; Hamidah et al., 2019; Mahfud et al., 2018; Mahfud et al., 2019; Quigley et al., 2019; Yang et al., 2020). Besides, the development of culinary tourism cannot be separated from aspects of the cultural heritage of food from their ancestors. So the development of culinary tourism often involves elements of traditional food. The involvement of traditional food in the development of culinary tourism aims to preserve the local cultural heritage of the ancestors. It seems that tourists support this destination; tourists choose traditional food as their consumption when they travel for reasons to respect local culture (Hiram Ting et al., 2019). Also, diverse interests and acceptance of food from various cultures have encouraged people to explore alternative food choices (Barrena and Sánchez, 2013).

Their awareness to try exotic cuisine, including local or ethnic food, is increasingly developing as technology and information develop through social media (Burgess, 2014). Now, the experience of tourism in the form of consuming traditional food is increasingly popular and has been widely developed as a local culinary tour (Burgess, 2014; Nor et al., 2012; Hiram Ting et al., 2019; Verbeke and López, 2005).

The presence of traditional food in culinary tourism activities influence the interest of tourists to visit tourist destinations. Collaborating on traditional food and tourist destinations is the right way to develop tourist destinations and culinary tour ism as well. This concept provides tourist knowledge about people, the environment, and culture through the exploration of traditional food (Tong et al., 2016). In principle, traditional food has a role in promoting tourism because tourists gain traditional and authentic food experiences in certain cultures (Rand et al., 2003). Also, scholar (for instance, Kim and Iwashita, 2016; H. Ting et al., 2016) has proven that food tourism preferences have an impact on individual behaviour in choosing their travel destinations.

Thus, both aspects consisting of traditional food and tourist destinations, are essential for developing culinary tourism. The main challenge in developing culinary tourism is presenting culinary tourism that suits different tourist preferences from various countries and cultures (Lin et al., 2011; Min and Lee, 2014). Another challenge, the development of traditional food tourism is competing closely with the development of modern food from various countries. Both of these challenges become serious challenges to promote traditional food. Therefore, information about preferences and their constituent factors is critical. Although there have been many studies that show that traditional food has an essential role in the development of sustainable tourism, there are still limited studies that examine the exploration of the antecedent factors of tourists' intentions to choose traditional food as their consumption when they travel.

\footnotetext{
* Corresponding author
} 
Nowadays, food / gastronomic tourism has become an exciting and popular field of tourism studies. However, there is still little information about the interests of both local and international tourists in choosing traditional foods in Southeast Asia as their tourism consumption choices. Specifically, how the intention of tourists to choose traditional Malaysian and Indonesian food is still limited. Malaysia and Indonesia share a common culture, so it is not surprising that many cultural similarities are found, including traditional foods in both countries. Besides, acceptance of traditional foods in Southeast Asia has experienced a good increase (Chang et al., 2011; World Trade Organization, 2017). The report shows that the traditional food of Southeast Asia, especially Malaysia and Indonesia, has excellent potential to be developed as alternative culinary tourism. Therefore, the development and promotion efforts need to be increased by considering the diversity of cultural backgrounds of local and international tourists.

An understanding of tourist preferences for traditional foods and their antecedent factors is crucial to be studied. Information about the structure forming the intention of tourists in choosing traditional foods when traveling is useful for developing culinary tourism by considering the cultural diversity of the tourists. Although Malaysia and Indonesia have great potential in the reception of traditional foods in Southeast Asia, there is still little information that presents perceptions of traditional food choices for tourists when they travel. In particular, there is still little information about the antecedent factors in the formation of the intention to consume traditional foods of tourists. This study aims to reveal the antecedent factors of the intention to consume traditional foods of tourists when traveling in Malaysia and Indonesia. Besides, this study also seeks to reveal the comparison of each antecedent factor between tourists in Malaysia and Indonesia.

\section{The role of traditional food in tourism activities}

The definition of traditional food is characterized into four dimensions, namely: (1) the product is often consumed from time to time or related to a particular celebration or season; (2) products related to strong beliefs about nutritional and sensory characteristics that must be transmitted from one generation to another; (3) preparation and consumption are specific, following gastronomic inheritance; and (4) products are closely related to certain areas, regions, or countries (Boncinelli et al., 2017; Guerrero et al., 2009). Traditional foods are part of the cultural heritage of certain regions (Bhaskarachary et al., 2016; Ferguson et al., 2017) and play a role in the transfer of cultural heritage to future generations (Albayrak and Gunes, 2010). Also, traditional meanings contribute to the development and sustainability of rural areas, protecting them from depopulation, involving substantial products of differentiation potential for producers and processors (Avermaete et al., 2004).

Food choice is an essential attribute for tourists, especially about the attractiveness of visited tourist destinations (Giampiccoli and Kalis, 2012; Remmington and Yuksel, 1998). Food reasons are often the reason tourists visit tourist destinations. Previous studies have shown that authentic and attractive local food can influence tourist decisions when choosing their vacation destinations (Ab Karim and Chi, 2010). This is quite reasonable because the involvement of traditional foods can provide an exciting experience for tourists during a tour. Their tourism activities can be used as an experience to learn about the culture and identity of tourist destinations. According to Kunwar (2017), traditional food does not only depend on the specificity of taste but also acts as a channel to know and experience a new culture. Smith and Xiao (2008) report that tourists no longer only eat to satisfy hunger but to learn and experience local culture through local ethnic food. Therefore, the experience of consuming traditional food is often included as part of a tour package to enhance the experience of tourists.

\section{Traditional food consumption intention}

Food choices in tourism activities have become an essential aspect in the development of tourism activities. Even authentic food is a platform to introduce and understand the local culture for visiting tourists. In principle, food choices are part of the study of human behaviour. This voting behaviour is influenced by many factors, such as situational and personal factors. Scholar (Prescott et al., 2002) states that the criteria for choosing food are an embodiment of several factors that affect sensory and non-sensory functions. Besides, other factors that influence food choices are personal (such as motives and intentions) to be a precursor to food consumption behaviour (Babicz-Zielińska, 2006; Mak et al., 2012). Specifically, Rozin (1996) argues that cultural background has a strong influence on food choices. Tourist choices will adjust to their eating habits and sensory properties.

Travelers when choosing food consider several factors such as sensory characteristics (such as taste, smell, and texture) and non-sensory characters such as attitudes related to food (Rozin, 1996), health (Filimonau et al., 2018), price (Steenhuis et al., 2011), and ethics (Dowd and Burke, 2013). However, some scholars (Babicz-Zielińska, 2006; Mak et al., 2012) emphasized the importance of personal factors such as motives and intentions as essential determinants of food consumption behaviour. The findings of previous studies indicate that individual intentions are significant in the study of traditional food choices for tourists. Good information about how the behaviour of tourists in choosing food is vital, especially for developing culinary tourism.

\section{Theory of Planned Behaviour (TPB) in traditional food consumption intention}

The intention of tourists to consume traditional foods is part of the study of personality traits. Therefore, this study is very appropriate to use the Theory of Planned Behaviour (TPB) approach to express the intention of tourists to consume traditional Malaysian and Indonesian food. TPB has been widely implemented in various research fields, including food consumption intentions (Dowd \& Burke, 2013; McDermott et al., 2015). This theory is based on the idea that the intention to perform certain behaviours is shaped by the desire of individuals to carry out their behaviour and belief in their ability to do that. Also, TPB emphasized that the most proximal determinant of behaviour was the intention to carry out that behaviour. The intention is believed to be able to direct individuals to carry out a behaviour. However, this intention also depends on attitude, overall evaluation of behaviour, and normal sufficiency.

In Theory of Planned Behaviour (TPB), it is revealed that individual behavioural intentions are determined by three aspects, namely (a) attitudes towards the behaviour, (b) subjective norms, and (c) perceived behavioural control (Ajzen, 1991, 2011). Attitudes towards the behaviour refer to the extent to which a person has a favorable or unacceptable evaluation or assessment of the planned behaviour. Subjective norms refer to the perceived social pressure to do or not do the behaviour. Finally, perceived behavioural control refers to the ease or difficulty that is felt in conducting behaviour and is assumed to reflect past experiences and anticipate obstacles and barriers. Ultimately this theory concludes that the more beneficial attitudes and subjective norms concerning behaviour, and the greater the perceived behavioural control, the stronger the individual's intention to carry out the planned behaviour (Ajzen, 2011).

Referring to TPB theory, then in the context of this study, attitudes towards the behaviour relate to an individual's evaluation of the selfperformance of traditional food consumption behaviour. Subjective norms are the expectations of others (social) towards those who consume traditional food. Meanwhile, perceived behavioural control refers to the ease or difficulty that is felt to consume traditional foods. Malaysia and Indonesia have a lot in common because they both come from Malay culture; these cultural similarities include traditional food culture. However, there is still little information that explains how intention tourists are in choosing traditional Malaysian and Ind onesian food when they travel. Specifically, how to compare the intention of Malaysian and Indonesian tourists in choosing traditional foods in their travel. 


\section{Research Conceptual Framework}

The development of this research model uses the TPB approach as a theoretical foundation. Based on TPB theory, we believe that the intention of tourists to choose traditional Malaysian and Indonesian foods when taking a tour is influenced by attitudes towards consuming traditional foods, subjective norms towards traditional foods, and behavioural control over traditional foods. The interaction and collaboration of the three independent variables play an essential role in determining the extent to which tourists' intentions to choose traditional foods and how those intentions are formed. Specifically, we examine the relationship between antecedents and the hierarchical structure of the antecedent factors of intention to consume traditional foods.

Although many scholars have discussed the role of these three aspects to shape food consumption intentions, empirical studies examining how the hierarchical structure of these three factors influence the intention to consume traditional foods are still minimal. The conceptual model in Figure 1 presents the direct and mediating effects between the factors of attitudes towards consuming traditional foods, subjective norms on traditional foods, behavioural control of traditional foods, and intention to consume traditional foods. This study also examines the role of mediating behavioural control of traditional foods in the interaction of attitudes towards the consumption of traditional foods, subjective norms on traditional foods, and intention to consume traditional foods of Malaysia and Indonesia. In this study, we tested the following hypotheses:

$\mathrm{H} 1$ = Attitude towards consuming traditional food has a positive effect on traditional food consumption intention among tourists.

$\mathrm{H} 2$ = Subjective norm towards consuming traditional food has a positive effect on traditional food consumption intention among tourists.

H3 = Perceived control towards consuming traditional food has a positive effect on traditional food consumption intention among tourists.

$\mathrm{H} 4=$ Attitude towards consuming traditional food has a positive effect on perceived control towards consuming traditional food among tourist.

H5 = Subjective norm towards consuming traditional food has a positive effect on perceived control towards consuming traditional food among tourist.

H6 = Perceived control towards consuming traditional food mediates the effect of the attitude towards consuming traditional food on traditional food consumption intention among tourists.

$\mathrm{H} 7$ = Perceived control towards consuming traditional food mediates the effect of the subjective norm towards consuming traditional food on traditional food consumption intention on tourists.

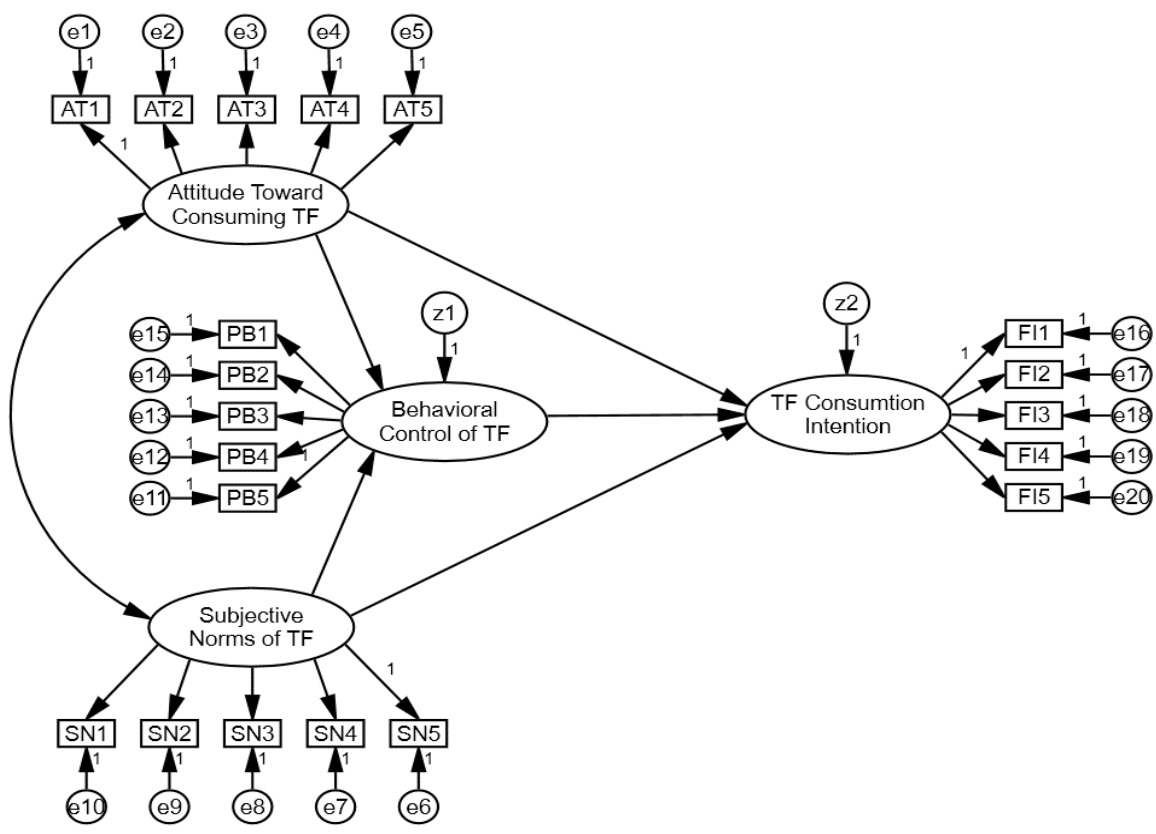

Figure 1. The conceptual framework

Note: AT1-AT5= items of attitude toward consuming traditional food; SN1-SN5= items of subjective norms of traditional food; PB1-PB5= items of behavioural control of traditional food; FI1-FI5= traditional food consuming intention

\section{MATERIAL AND METHODS}

This study focuses on exploring the antecedent factors of tourists' intention to consume traditional foods. The online questionnaire was randomly distributed to Indonesian and Malaysian tourists who were touring. Four hundred sixty-two tourists completed the survey, consisting of 242 Indonesian tourists and 220 Malaysian tourists (Table 1).

We collected data using a questionnaire from a previous study (Hiram Ting et al., 2019), and we developed a questionnaire. The questionnaire that we have developed is used to measure tourist perceptions about attitudes toward consuming traditional food, subjective norms of traditional food, behavioural control of traditional food, and consuming intention of traditional food. The original questionnaire consisted of three items on each of these variables.

Meanwhile, the questionnaire in this study amounted to 20 items consisting of 5 items attitude toward consuming traditional food (For example, I will try traditional food when I tour), five items subjective norms of traditional food (For instance, I will try traditional food, if important people encourage me to do that), five items behavioural control of traditional food (for example, I have personal control to choose traditional food as food during my tour), five items consuming intention of traditional food (for instance, I plan to consume traditional food when I tour). All variables in this study take a five-point Likert scale (strongly disagree to agree strongly).

We use structural equation modeling (SEM) with the help of Amos 18 software to test structural models of tourists' intention to consume traditional foods. The coefficients of the structural model are evaluated through a review of various goodness-of-fit criteria. The match test is intended to assess the degree of compatibility between empirical data and the model. Meanwhile, the mediation role test uses a bootstrapping confidence interval with 500 bootstrap sample criteria and a $90 \%$ confidence level. 
Table 1. Background of participants $(\mathrm{N}-462)$

\begin{tabular}{|l|l|c|c|}
\hline \multicolumn{1}{|c|}{ Attribute } & \multicolumn{1}{|c|}{ Categories } & N & \% \\
\hline \multirow{4}{*}{ Country } & Indonesia & 242 & 52.4 \\
\cline { 2 - 4 } & Malaysia & 220 & 47.6 \\
\hline \multirow{5}{*}{ Pender } & Male & 157 & 34 \\
\cline { 2 - 4 } & Female & 305 & 66 \\
\hline \multirow{5}{*}{ Educational background } & Government employees & 128 & 27.7 \\
\cline { 2 - 4 } & Employee state-owned enterprise & 3 & 0.6 \\
\cline { 2 - 4 } & Private employees & 38 & 8.2 \\
\cline { 2 - 4 } & Entrepreneur & 4 & 0.9 \\
\cline { 2 - 4 } & Student & 251 & 54.3 \\
\cline { 2 - 4 } & Others & 38 & 8.2 \\
\cline { 2 - 4 } & Elementary school & 1 & 0.2 \\
\cline { 2 - 4 } & High school & 90 & 19.5 \\
\cline { 2 - 4 } & Bachelor degree & 240 & 51.9 \\
\cline { 2 - 4 } & Master degree & 48 & 18 \\
\cline { 2 - 4 } & Doctoral degree & & 10.4 \\
\hline
\end{tabular}

\section{RESULTS AND DISCUSSION}

\section{Results}

Validity and reliability

The validity test results using SEM analysis show all items have a loading factor value above 0.5 (Table 2); this means all items are declared valid. Ghozali (2017) states that the critical limit value used is the loading factor or the parameter value $\lambda$ of at least 0.5 . Also, we tested the reliability of the questionnaire for each variable. The construct reliability test results on all variables showed values above 0.7 . Thus, the questionnaire in this study has the reliability to measure attitudes toward consuming traditional food, subjective norms of traditional food, behavioural control of traditional food, and consuming intention of traditional food for tourists.

Table 2. Validity and Reliability of the Instrument in this Study

\begin{tabular}{|l|c|c|}
\hline \multicolumn{1}{|c|}{ Variables (N) } & Loading Factor (Validity) & Construct Reliability \\
\hline Attitude toward consuming of traditional food (AT1-AT5) & $.774^{* * *}-.941^{* * *}$ & .995 \\
\hline Subjective norms of traditional food (SN1-SN5) & $.532^{* * *}-.897^{* * *}$ & .988 \\
\hline Behavioural control of traditional food (PB1-PB5) & $.606^{* * *}-.921^{* * *}$ & .989 \\
\hline Consuming intention of traditional food (FI1-FI5) & $.770^{* * *}-.949 * * *$ & .995 \\
\hline
\end{tabular}

Note. *** Very small p-value (smaller than 0.001$)$

The systematic and hierarchical structure of antecedent factors of traditional food consumption intention

The SEM analysis results are shown in Figure 2. The results of the SEM analysis showed that most goodness of fit criteria met proper criteria (Table 3). Next, we tested the effect of each variable that was hypothesized.

Table 3. Goodness of Fit Criteria

\begin{tabular}{|l|l|l|l|}
\hline \multicolumn{1}{|c|}{ Goodness of Fit Measure } & Index Value & \multicolumn{1}{c|}{ Cut off-value } & Note \\
\hline df & 164 & & Not fit model \\
\hline Chi-square of estimate model & 553.061 & $<2 \mathrm{df}$ & Not fit model \\
\hline Probability level & 0.000 & $>0.05$ & Fit model \\
\hline Cmin/df & 3.372 & $\leq 5$ & Marginal fit \\
\hline Goodness of Index (GFI) & 0.878 & GFI $\geq 0.9=$ good fit; $0.8 \leq$ GFI $<0.9=$ marginal fit & Marginal fit \\
\hline Adjusted Goodness of Index (AGFI) & 0.843 & AGFI $\geq 0.9=$ good fit; $0.8 \leq$ AGFI $<0.9=$ marginal fit & Fit model \\
\hline RMSEA & 0.072 & $\leq 0.08$ & Fit model \\
\hline RMR & 0.039 & $<0.05$ & Fit model \\
\hline Tucker-Lewis Index (TLI) & 0.945 & TLI $\geq 0.9=$ good fit; $0.8 \leq$ TLI $<0.9=$ marginal fit \\
\hline Comparative Fit Index (CFI) & 0.952 & CFI $\geq 0.9=$ good fit; $0.8 \leq$ CFI $<0.9=$ marginal fit & Fit model \\
\hline Normed Fit Index (NFI) & 0.934 & NFI $\geq 0.9=$ good fit; $0.8 \leq$ NFI $<0.9=$ marginal fit & Fit model \\
\hline
\end{tabular}

The first hypothesis testing shows the acquisition of Regression Weights (p-value) of $.394(\mathrm{p}=* * *)$, so the first hypothesis is accepted (Table 4). This finding means that the attitude towards consuming traditional food has a positive effect on traditional food consumption intention among tourists. Besides, testing the second hypothesis shows the results of the hypothesis are accepted $(\mathrm{p}=.035)$. This result means that subjective norm towards consuming traditional food has a positive effect on traditional food consumption intention among tourists. The third hypothesis testing shows that perceived control towards consuming traditional food has a positive impact on traditional food consumption intention among tourists (hypothesis accepted, $\mathrm{p}=* * *$ ).

Furthermore, testing the fourth hypothesis shows that attitude towards consuming traditional food has a positive effect on perceived control towards consuming traditional food among tourists (hypothesis accepted, $\mathrm{p}=* * *$ ). Testing the last direct path hypothesis (H5) shows that subjective norm towards consuming traditional food has a positive effect on perceived control towards consuming traditional food among tourists (hypothesis accepted, $\mathrm{p}=* * *$ ). Thus, testing the path analysis on the direct impact on each variable shows that the overall effect is directly on the path being hypothesized.

Testing the role of behavioural control mediators using the bootstrapping confidence interval method with 500 bootstrap sample criteria and a $90 \%$ confidence level. The results of testing the mediator role (Table 5) reveal that perceived control towards consuming traditional food is a vital mediator to strengthen the influence of attitude and subjective norms on consuming intention of traditional food among tourists. Specifically, the sixth hypothesis testing showed that perceived control towards consuming traditional food significantly mediates the effect of the attitude towards consuming traditional food on traditional food consumption intention among tourists $(.201, \mathrm{p}=$ $.002, \mathrm{CI}=.136 \sim .294$ ), representing partial mediation; thus, Hypothesis 6 was supported (Preacher \& Hayes, 2008). 


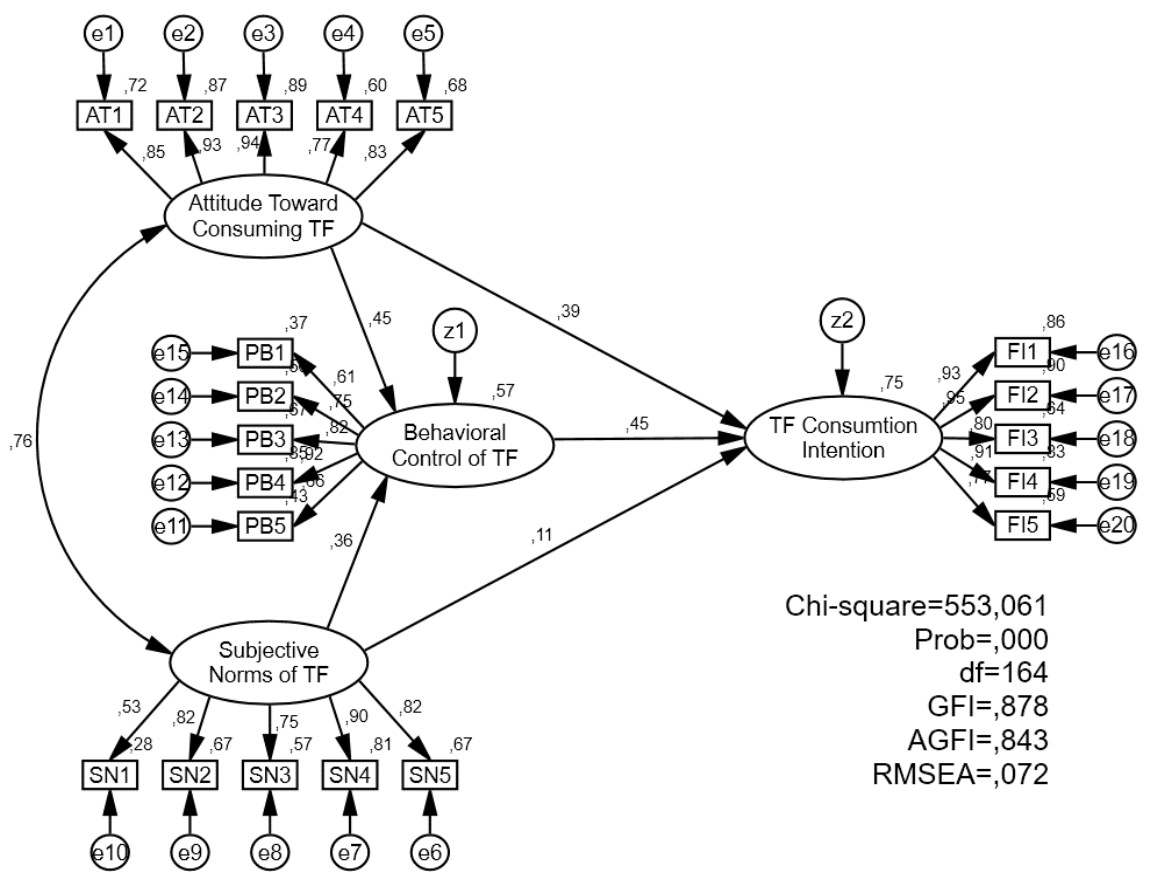

Figure 2. SEM Analysis Results (Full Model)

Note: AT1-AT5= items of attitude toward consuming traditional food; SN1-SN5= items of subjective norms of traditional food; PB1-PB5= items of behavioural control of traditional food; FI1-FI5= traditional food consuming intention

According to Baron and Kenny (1986), partial mediation indicates the influence of the independent variable on the dependent variable and the effect of the mediator variable on the dependent variable. Besides, perceived control towards consuming traditional food also significantly mediates the effect of the subjective norm towards consuming traditional food on traditional food consumption intention on tourists $(.161, \mathrm{p}=.001, \mathrm{CI}=.108 \sim .257)$ and representing partial mediation, so Hypothesis 7 was supported.

Table 4. The path analysis results in Full Model SEM (standardized regression weights)

\begin{tabular}{|l|c|c|c|c|c|}
\hline & Estimate & S.E. & C.R. & P & Result \\
\hline $\mathrm{AT} \rightarrow$ FI & .394 & .053 & 7.671 & $* * *$ & Significant \\
\hline $\mathrm{SN} \rightarrow$ FI & .105 & .051 & 2.104 & .035 & Significant \\
\hline $\mathrm{PB} \rightarrow$ FI & .448 & .074 & 8.576 & $* * *$ & Significant \\
\hline $\mathrm{AT} \rightarrow$ PB & .447 & .048 & 6.861 & $* * *$ & Significant \\
\hline SN $\rightarrow$ PB & .360 & .047 & 5.530 & $* * *$ & Significant \\
\hline
\end{tabular}

Note. $* * *=$ Correlation is significant at the 0.001 level; AT $=$ attitude toward consuming of traditional food;

$\mathrm{SN}=$ subjective norms of traditional food; $\mathrm{PB}=$ behavioural control of traditional food; $\mathrm{FI}=$ consuming intention of traditional food

This finding indicates that behavioural control towards consuming traditional food is a vital mediator to optimize the influence of attitude and subjective norm of consuming traditional food among tourists. Also, attitude, subjective norms, and behavioural control are crucial factors to encourage tourists to consume traditional food during their tour.

Table 5. The result of bootstrapping in testing the mediator perceived control towards consuming traditional food

\begin{tabular}{|c|l|c|c|}
\hline Effect & Path & AT $\rightarrow$ PB $\rightarrow$ FI & SN $\rightarrow$ PB $\rightarrow$ FI \\
\hline \multirow{2}{*}{ Standardized indirect effect (PB mediator) } & Estimate & .201 & .161 \\
\cline { 2 - 4 } & P-value & .002 & .001 \\
\hline
\end{tabular}

Note: AT= attitude toward consuming of traditional food; $\mathrm{SN}=$ subjective norms of traditional food;

$\mathrm{PB}=$ behavioural control of traditional food; $\mathrm{FI}=$ consuming intention of traditional food.

Discussion

Traditional food is one of the essential potentials in developing cultural-based culinary tourism. A good understanding of tourist preferences and factors that influence tourists to consume traditional food is a vital study for the development of sustainable tourism, especially culinary tourism. This study aims to examine the antecedent factors forming the intention of tourists to consume traditional foods during their tour.

The results of this study reveal that the intention of tourists to consume traditional foods is influenced by three crucial factors consisting of attitude, subjective norms, and behavioural control of tourists to consume traditional foods. This finding reinforces previous studies conducted by Hiram Ting et al. (2019), his research also shows that three essential aspects influence the intention of tourists to consume ethnic food in Theory of Planned Behaviour (TPB). The attitude of tourists about their assessment of traditional food has a vital role in encouraging the intention to consume traditional food. The more they have a positive evaluation of traditional food on their tour, the more they will increase their confidence to try traditional food. Another vital aspect is subjective norms; this aspect illustrates the extent of the influence of social assessment of traditional foods on tourists' decisions to consume traditional foods. This study shows that positive recommendations and reviews from others and the mass media influence the intention of tourists to try traditional foods when they travel.

Another interesting finding, when compared to the three antecedents of intention to consume traditional foods, it was found that behavioural control had the most significant and significant influence. These results reinforce the TPB theory, which states that the 
higher the perceived behavioural control, the stronger the individual's intention to carry out the planned behaviour (Ajzen, 2011). Behavioural control illustrates the ease and difficulty of tourists to consume traditional food when they travel. The higher the perceived ease of consuming traditional foods, the greater the plan to try traditional foods when they were touring. This study places the behavioural control factor as the most contributory factor in the intention to consume traditional foods, which makes sense. Because after all, individual intentions are primarily determined by their beliefs about planned behaviour (Ajzen, 2011; Mahfud et al., 2019; Mahfud et al., 2019).

Another finding is that behavioural control of tourists about traditional food is influenced by attitude and subjective norms. That is, although behavioural control as the most significant factor contributes to affect the intention of tourists to consume traditional foods, behavioural control is very dependent on the extent of attitudes and social judgments about traditional foods. If attitudes and subjective norms have a positive assessment of traditional food, it will encourage tourists to feel confident and young to consume traditional foods. Thus, this study places behavioural control as a mediator to strengthen the influence of attitude and subjective norms on tourist intentions to consume traditional food. Overall, the results of this study support the Theory of Planned Behaviour (TPB) by using the context of tourists' intentions to consume traditional food.

This study has implications for tourism practitioners in the development of cultural-based culinary tourism, especially in Malaysia and Indonesia. Traditional food can be an alternative to introducing local culture to tourists through food. Also, traditional food used as a culinary tourism product can support the preservation of cultural heritage programs in each region. The development of culinary touris $m$ by considering tourist preferences and other essential aspects is something that needs to be considered by tourism practitioners.

\section{CONCLUSION}

The results of this study reveal that attitude, subjective norms, and behavioural control are important antecedent factors to influence tourists' intentions to consume traditional foods. In this context, behavioural control factors have the most significant contribution to shaping tourist intentions. However, tourists' perceptions about behavioural control to consume traditional foods depend on their attitude and subjective norms on traditional foods. This study also highlights the vital role of behavioural control as a mediator to strengthen the influence of attitude and subjective norms on tourist intentions to consume traditional foods. Finally, the results of this study have implications for tourism practitioners to consider tourist preferences and other essential factors in developing cultural-based culinary tourism.

\section{Acknowledgement}

The authors want to acknowledge that this research has been carried out in Malaysia and Indonesia. The authors wished to thank the tourists involved in providing data for this paper. Also, the authors wished to thank the Institute for Research and Community Service of Yogyakarta State University for research funding support. Finally, the authors acknowledge to anonymous reviewer for their thoughtful suggestions and comments.

\section{REFERENCES}

Ab Karim, S., \& Chi, C.G.Q. (2010). Culinary Tourism as a Destination Attraction: An Empirical Examination of Destinations' Food Image. Journal of Hospitality Marketing \& Management, 19(6), 531-555. https://doi.org/10.1080/19368623.2010.493064

Ahlawat, M., Sharma, P., \& Gautam, P.K. (2019). Slow food and tourism development: A case study of slow food tourism in uttarakhand, india. GeoJournal of Tourism and Geosites, 26(3), 751-760. https://doi.org/10.30892/gtg.26306-394

Ajzen, I. (1991). The theory of planned behavior. Organizational Behavior and Human Decision Processes, 50(2), 179-211. https://doi.org/ 10.1016/07495978(91)90020-T

Ajzen, I. (2011). The theory of planned behaviour: Reactions and reflections. Psychology \& Health, 26(9), 1113-1127. https:/doi.org/10. $1080 / 08870446.2011 .613995$

Albayrak, M., \& Gunes, E. (2010). Traditional foods: Interaction between local and global foods in Turkey. African Journal of Business Management, 4(4), 555-561. https://www.semanticscholar.org/paper/Traditional-foods\%3A-Interaction-between-local-and-in-Albayrak-Gunes/8ac692f62d09cd97ef6aa8212 $\mathrm{c} 87565 \mathrm{c} 4604 \mathrm{fc} 30$

Avermaete, T., Viaene, J., Morgan, E.J., Pitts, E., Crawford, N., \& Mahon, D. (2004). Determinants of product and process innovation in small food manufacturing1The content of the paper is the responsibility of the first three authors. firms1. Trends in Food Science \& Technology, 15(10), 474-483. https://doi.org/10.1016/j.tifs.2004.04.005

Babicz-Zielińska, E. (2006). Role of psychological factors in food choice-a review. Pol Polish Journal of Food and Nutrition Sciences, 15(56), 379-384.

Barrena, R., \& Sánchez, M. (2013). Neophobia, personal consumer values and novel food acceptance. Food Quality and Preference, 27(1), 72-84. https://doi.org/10.1016/j.foodqual.2012.06.007

Bhaskarachary, K., Vemula, S.R., Gavaravarapu, S.R.M., \& Joshi, A.K.R. (2016). Traditional foods, functional foods and nutraceuticals. Proceedings of the Indian National Science Academy, 1565-1577. https://doi.org/10.16943/ptinsa/2016/48888

Boncinelli, F., Contini, C., Romano, C., Scozzafava, G., \& Casini, L. (2017). Territory, environment, and healthiness in traditional food choices: insights into consumer heterogeneity. International Food and Agribusiness Management Review, 20(1), 143-157. https://doi.org/10.22434/IFAMR2015.0177

Burgess, P.J. (2014). Modification of a traditional Korean food product (Gochujang) to enhance its consumer acceptability as an ethnic food. Journal of Ethnic Foods, 1(1), 13-18. https://doi.org/10.1016/j.jef.2014.11.005

Chang, R.C.Y., Kivela, J., \& Mak, A.H.N. (2011). Attributes that influence the evaluation of travel dining experience: when East meets West. Tourism Management, 32(2), 307-316. https://doi.org/10.1016/j.tourman.2010.02.009

Dowd, K., \& Burke, K.J. (2013). The influence of ethical values and food choice motivations on intentions to purchase sustainably sourced foods. Appetite, 69, 137-144. /https://doi.org/10.1016/j.appet.2013.05.024

du Rand, G. E., Heath, E., \& Alberts, N. (2003). The role of local and regional food in destination marketing. Journal of Travel \& Tourism Marketing, 14(34), 97-112. https://doi.org/10.1300/J073v14n03_06

Ellis, A., Park, E., Kim, S., \& Yeoman, I. (2018). What is food tourism? Tourism Management, 68, 250-263. https://doi.org/10.1016/j.tourman.2018.03.025

Ferguson, M., Brown, C., Georga, C., Miles, E., Wilson, A., \& Brimblecombe, J. (2017). Traditional food availability and con sumption in remote Aboriginal communities in the Northern Territory, Australia. Australian and New Zealand Journal of Public Health, 41(3), 294-298. https://doi.org/10.1111/1753-6405.12664

Filimonau, V., Matute, J., Durydiwka, M., Faracik, R., Mika, M., \& Zajadacz, A. (2018). The determinants of more responsible restaurant food choice in Poland. Journal of Sustainable Tourism, 26(8), 1398-1416. https://doi.org/10.1080/09669582.2018.1456542

Ghozali, I. (2017). Structural equation models: Concepts and applications with the AMOS 24 bayesian SEM update program (Indonesian version) (Edisi 7). Semarang: Badan Penerbit Universitas Diponegoro.

Giampiccoli, A., \& Kalis, J.H. (2012). Tourism, food, and culture: Community-based tourism, local food, and community development in Mpondoland. Culture, Agriculture, Food and Environment, 34(2), 101-123. https://doi.org/10.1111/j.2153-9561.2012.01071.x

Guerrero, L., Guàrdia, M., Xicola, J., Verbeke, W., Vanhonacker, F., Zakowska-Biemans, S., \& Hersleth, M. (2009). Consumer-driven definition of traditional food products and innovation in traditional foods. A qualitative cross-cultural study. Appetite, 52, 345-354. https://doi.org/https://doi.org/10.1016/j.appet.2008.11.008 
Hamidah, S., Komariah, K., \& Lastariwati, B. (2019). Implementation of innovative learning of culinary productive towards mastery competency 21 st century. Journal of Physics: Conference Series, 1273(1). https://doi.org/https://doi.org/10.1088/1742-6596/1273/1/012050

Ian, Y. (2016). The future of food tourism. Journal of Tourism Futures, 2(1), 95-98. https://doi.org/10.1108/JTF-12-2015-0051

Kim, S., \& Iwashita, C. (2016). Cooking identity and food tourism: The case of Japanese udon noodles. Tourism Recreation Research, 41(1), 89-100. https://doi.org/https://doi.org/10.1080/02508281.2016.1111976

Kunwar, R. (2017). Food tourism revisited. Journal of Tourism and Hospitality Education, 7, 83-124. https://doi.org/10.3126/jthe.v7i0.17691

Lin, Y.C., Pearson, T.E., \& Cai, L.A. (2011). Food as a form of destination identity: A tourism destination brand perspective. Tourism and Hospitality Research, 11(1), 30-48. Retrieved from http://www.jstor.org/stable/23745424

Mahfud, T., Indartono, S., Saputro, I.N., \& Utari, I. (2019). The effect of teaching quality on student career choice: The mediating role of student goal orientation. Integratsiya Obrazovaniya = Integration of Education, 23(4), 541-555. https://doi.org/10.15507/1991-9468.097.023.201904.541-555

Mahfud, T., Mulyani, Y., Indartono, S., \& Setyawati, R. (2018). Community-based tourism development: Foodies community strategy to culinary tourism development in Balikpapan-Indonesia. Journal of Tourism and Management Research, 3(2), 274-289. https://www.semanticscholar. org/paper/Community-based-tourism-development\%3A-foodies-to-in-Mahfud- Mulyani/8e1 ef5e4c4032f933ab81a6fd450 09d5afdb697c

Mahfud, T., Pardjono, \& Lastariwati, B. (2019). Chef's competency as a key element in food tourism success: A literature review. Geojournal of Tourism and Geosites, 26(3), 1057-1071. https://doi.org/10.30892/gtg.26329-417

Mahfud, T., Triyono, M.B., Sudira, P., \& Mulyani, Y. (2019). The influence of social capital and entrepreneurial attitude orientation on entrepreneurial intentions: the mediating role of psychological capital. European Research on Management and Business Economics, 26, 1, 33-39, https:// doi.org/10.1016/j.iedeen.2019.12.005

Mak, A.H., Lumbers, M., Eves, A., \& Chang, R.C. (2012). Factors influencing tourist food consumption. International Journal of Hospitality Management, 31(3), 928-936. https://doi.org/https://doi.org/10.1016/j.ijhm.2011.10.012

McDermott, M.S., Oliver, M., Svenson, A., Simnadis, T., Beck, E.J., Coltman, T., \& Sharma, R. (2015). The theory of planned behaviour and discrete food choices: a systematic review and meta-analysis. The International Journal of Behavioral Nutrition and Physical Activity, 12, 162. https://doi.org/10.1186/s12966-015-0324-Z

Min, K.H., \& Lee, T.J. (2014). Customer satisfaction with Korean restaurants in Australia and their role as ambassadors for tourism marketing. Journal of Travel \& Tourism Marketing, 31(4), 493-506. https://doi.org/https://doi.org/10.1080/10548408.2013.877412

Nor, N.M., Sharif, M.S. M., Zahari, M.S.M., Salleh, H.M., Isha, N., \& Muhammad, R. (2012). The Transmission Modes of Malay Traditional Food Knowledge within Generations. Procedia - Social and Behavioral Sciences, 50, 79-88. https://doi.org/10.1016/j.sbspro.2012.08.017

Prescott, J., Young, O., O’Neill, L., Yau, N.J.N., \& Stevens, R. (2002). Motives for food choice: a comparison of consumers from Japan, Taiwan, Malaysia and New Zealand. Food Quality and Preference, 13(7), 489-495. https://doi.org/10.1016/S0950-3293(02)00010-1

Quigley, K., Connolly, M., Mahon, E., \& Iomaire, M.M.C. (2019). Insight from insiders: A phenomenological study for exploring food tourism policy in Ireland 2009-2019. Advances in Hospitality and Tourism Research, 7(2), 188-215. https://doi.org/10.30519/ahtr.574519

Remmington, M., \& Yuksel, A. (1998). Tourist satisfaction and foodservice experience: Results and implications of an empirical investigation. Anatolia, 9(1), 37-57. https://doi.org/https://doi.org/10.1080/13032917.1998.9686958

Rozin, P. (1996). The socio-cultural context of eatingand food choice. In H. Meiselman \& H.J.H. MacFie (Eds.), Food choice, acceptance and consumption (83-104). London: Blackie. https://link.springer.com/chapter/10.1007/978-1-4613-1221-5_2

Sims, R. (2009). Food, place and authenticity: local food and the sustainable tourism experience. Journal of Sustainable Tourism, 17(3), 321-336. https://doi.org/10.1080/09669580802359293.

Smith, S.L., \& Xiao, H. (2008). Culinary tourism supply chains: A preliminary examination. Journal of Travel Research, 46(3), 289-299. https://doi.org/10.1177/0047287506303981

Steenhuis, I.H.M., Waterlander, W.E., \& de Mul, A. (2011). Consumer food choices: the role of price and pricing strategies. Public Health Nutrition, 14(12), 2220-2226. https://doi.10.1017/S1368980011001637

Ting, H., de Run, E.C., Cheah, J.H., \& Chuah, F. (2016). Food neophobia and ethnic food consumption intention: An extension of the theory of planned behaviour. British Food Journal, 118(11), 1-15. https://doi.org/https://doi.org/10.1016/j.jef.2017.02.005

Ting, H. Fam, K.S., Jun Hwa, J.C., Richard, J.E., \& Xing, N. (2019). Ethnic food consumption intention at the touring destination: The national and regional perspectives using multi-group analysis. Tourism Management, 71, 518-529. https://doi.org/10.1016/j.tourman.2018.11.001

Tong, X.F., Tong, D.Y.K., \& Tam, W.S. (2016). Food tourism: The Melaka gastronomic experience. Journal of Emerging Trends in Marketing and Management, 1(1), 236-246. https://ideas.repec.org/a/aes/jetimm/v1y2016i1p236-246.html

Verbeke, W., \& López, G. (2005). Ethnic food attitudes and behavior among Belgians and Hispanics living in Belgium. British Food Journal, 107, 823-840. https://doi.org/10.1108/00070700510629779

Yang, F.X., Wong, I.A., Tan, X.S., \& Wu, D.C.W. (2020). The role of food festivals in branding culinary destinations. Tourism Management Perspectives, 34, 100671. https://doi.org/10.1016/j.tmp.2020.100671

*** World Trade Organization. (2017). Tourism and travel-related services. Retrieved February 18, 2020, from https://www.wto.org/english/tratop_ e/serv_e/tourism_e/tourism_e.htm 